\title{
Cultivating motivational school-readiness for children with systemic speech disorders through the speech therapy
}

\author{
Natalia Berdnikova ${ }^{1, *}$ and Natalia Abashina ${ }^{2}$ \\ ${ }^{1}$ South Federal University, 105/42, 344006 Bolshaya Sadovaya Str., Rostov-on-Don, Russia \\ ${ }^{2}$ Don State Technical University, 3440031 Gagarina Pl, Rostov-on-Don, Russia
}

\begin{abstract}
The article examines the theoretic and methodological aspect, the technology of special education, aimed at developing motivational school-readiness education of children with systemic speech disorders. Motivational school-readiness to study is considered from various positions: from a social position (motives related to the need for communication, evaluation and approval, the desire to take a certain place in the system of social relations) and cognitive position (motives related to educational activities, the need for intellectual activity and the acquisition of new skills, skills and knowledge).
\end{abstract}

\section{Introduction}

Relevance of the study. Currently, a large role in the life of a child is assigned to the process of preparing for school. Often, the concept of «school-readiness» includes the child's mastery of such skills as writing, counting, solving arithmetic problems, and reading. Paying great attention to the above skills, other important components that are necessary for the future student are missed. Psychological school-readiness represents a systematic quality of the psyche of a child entering school, which gives him the opportunity to successfully start learning. In the most General form, the problem of school-readiness is the correspondence of the child's mental properties and qualities to the requirements of the school. The further development of the child's personality, the effectiveness of training, and professional development in the future depend on the level of preparation of the child for school. The problem of psychological readiness for school includes themselves the specific problems of motivational school-readiness.

The importance of the motivational component in the structure of school-readiness was emphasized by such authors as N. V. Nizhegorodtseva and T. V. Zhukova [1]. The problem of motivational school-readiness for children with systemic speech disorders has been studied and covered much less. Such researchers as L. A. Golovchits, O.V.Bekker [2] and others have dealt with the problem of readiness for school education of children with speech disorders, as well as the question of motivational readiness of children with systemic disorders. In the works of the above-mentioned authors, school-readiness was not

* Corresponding author: PlatohinaN@yandex.ru 
considered in isolation, but was considered in the context of other problems. In particular, L. A. Golovchits [2], in his research writes that children of this category have problems of speech development in the foreground.

Motives are the primary structural element of the activities. They show their influence at all stages and in all structural units of activity. The choice of means to achieve the results of activity, the nature of actions, operations of control and evaluation of the obtained result of activity depend on the nature of motives.

In the older preschool age, a special place among other motives is occupied by the cognitive motive. At the same time, cognitive activity is not a consequence of age. N.I. Gutkina [3] draws attention to the fact that today, such an important and valuable quality is reduced in most preschool children. It should also be considered that for children with systemic speech disorders, cognitive motives are often more important due to the need for such children to acquire new knowledge.

The theoretical and methodological basis of the research is based on scientific works of Russian and foreign authors:

- research of I.Yu. Levchenko, I.V. Evtushenko [4] and I. A. Emelyanova [5] considering the personal qualities of a preschooler with speech underdevelopment and characterized by specific features (low self-esteem, communication disorders, different in the severity of manifestations of anxiety and aggressiveness);

- in the works of A.N. Leontiev identified the following types of motivation: external motivation (motivation, not related to the content of a certain activity, but due to external circumstances); internal motivation (motivation associated not with external circumstances, but by the very content of a particular activity); positive and negative motivation (motivation based on positive stimulation is positive motivation; motivation based on negative incentives is called negative motivation);

- publications of E.Yu. Patyaeva, in which the types of learning situations are determined: the first situation is a spontaneous or natural learning characteristic of preschool children and persisting at an older age outside the sphere of organized learning; the second situation is a given (or forced) teaching prevailing in the education system; the third situation is selfdetermined teaching, which is mastered by younger students and which they master in subsequent years;

- scientific research N.V. Nizhegorodtseva, T.V. Zhukova [1] in which six groups of motives of future first-graders were identified: social, educational and cognitive; estimated; positional; external and play motives;

- in foreign studies of S.Hareli, U. Hess[6], the theoretical aspect of the problem of the development of personality motivation has been studied in detail;

- in scientific publications of I. Abdullah [7], P-J.Wang, A-W.Hwang [8], S.R.Zentall, B.J. Morris [9] described the experience of studying the stability of motivation in young children, the effect of the type of praise mismatch on the motivation of young children.

- in the studies of P.A. McDermott, S.H. Rikoon, C. Waterman, J.W. Fantuzzo [10], P. Haidkind., E. Kikas, H. Henno, T. Peets [11], M. Prior, E.Bavin, B.Ong [12], S.L. Bender [13] disclosed peculiarities of assessing the readiness for schooling of preschool children (diagnostic procedures, individual and mental characteristics of the subjects, interpretation of the results);

- in the works of C.Cipriani [14], the specifics of assessing the school-readiness of 5-8 years old children with impairments in the cognitive sphere, impaired in social-emotional and motor coordination are described;

- in the studies of M Guhn, A. Gadermann[15], M.Janus [16], A.Mousavi , V. Krishnan [17], J.E.V. Lloyd, C. Hertzman [18], P.A. McDermott [19] presents screening programs for assessing the level of development of children before entering school, a questionnaire for preschool teachers, consisting of 104 questions, which assesses five parameters - scales of 
early childhood development: physical health, social knowledge, emotional health, speech, cognitive development; communication skills;

-in the works of H.-Ju Kim, P.A McDermott, A.M Barsevick [20] describes the role of teaching practices in the development of children's interest in reading and mathematics in kindergarten;

- in the study of G. Melzi, A. R. Schick and K. Escobar [21] presented a methodology aimed at assessing the level of self-regulation of preschoolers;

- in his publication "On educational motivation of preschoolers with speech disorders" S.M. Valyavko [22] writes that the child's activity to correct speech disorders can be considered as an educational activity carried out within the framework of forced learning (imposed from the outside). The motivational readiness to study at school of children with speech impairments is considered from two positions: social (motives of learning or motives associated with the child's needs in communicating with other people, in their assessment and approval, with the desire to take a certain place in the system of public relations available to him) and cognitive (motives directly related to educational activities, or the cognitive interests of children, the need for intellectual activity and in mastering new skills, skills and knowledge);

- in his research V.N. Ponikarova, KA Kurochkina described the content of correctional and developmental work on the formation of speech readiness for schooling in children with speech disorders;

- in the works of E.O. Kanunnikova highlighted the effective conditions for the formation of communicative readiness to study at school in speech therapy classes: complex diagnostics; ensuring the gradual formation of communicative readiness to study at school; participation of the teaching staff, parents in ensuring the communicative orientation of the teaching process, upbringing of older preschool children with general speech underdevelopment.

In the analysis of psycholinguistic, neuropsychological, psychological-pedagogical and scientific-methodical literature, the study of the work experience of a preschool educational institution made it possible to identify discrepancies and contradictions between:

- the growing need of society and the state in teaching children with systemic speech disorders in conditions of training in a preschool educational institution and the existing education system focused on teaching and upbringing of children with full speech development;

- the need for further purposeful study of psychological mechanisms for the formation of motivational readiness for schooling in children with systemic speech disorders in speech therapy classes and insufficient development of this issue in the scientific literature;

- practical demand in speech therapy work for differentiated correctional and developmental technologies for the formation of motivational readiness to study at school for children with systemic speech disorders, and their insufficient development.

\section{The results of the research}

The experiment involved 20 children 6-7 years old with systemic speech disorders. During the study, we identified the level of motivational readiness for learning at school for preschoolers with general speech underdevelopment in accordance with the following criteria and indicators: 
Table 1. Criteria and indicators of motivational readiness for learning at school for preschoolers with general speech underdevelopment

\begin{tabular}{|c|c|}
\hline \multicolumn{1}{|c|}{ Criteria } & \multicolumn{1}{|c|}{ Indicators } \\
\hline $\begin{array}{l}\text { motivational } \\
\text { profile of a senior } \\
\text { preschool child }\end{array}$ & $\begin{array}{l}\text { educational and cognitive, } \\
\text { external, grade-oriented, game profile }\end{array}$ \\
\hline $\begin{array}{l}\text { the dominant type } \\
\text { of activity }\end{array}$ & play, educational, labor \\
\hline $\begin{array}{l}\text { readiness to } \\
\text { master literacy and } \\
\text { reading }\end{array}$ & $\begin{array}{l}\text { the level of development of } \\
\text { phonemic hearing, phonemic } \\
\text { perception, grammatical structure of } \\
\text { speech, vocabulary, word formation } \\
\text { skills, coherent speech, fine motor } \\
\text { skills }\end{array}$ \\
\hline
\end{tabular}

When examining preschoolers, the following diagnostic techniques were used: conversation-dialogue about school (by TA Nezhnova); "Determination of the motives of teaching" (by MR Ginzburg); methodology "Assessment of motivational readiness" (author DV Soldatov); diagnostics of readiness for literacy and reading (by OB Inshakova).

The experiment showed that $10 \%$ of children ( 2 children) were found with a high level of motivational readiness to study at school, with an average level $-35 \%$ of children (7 preschoolers), with a low level - 55\% of preschoolers (11 subjects). Obviously, the majority of preschoolers in the experimental group have a predominantly play motive, children do not demonstrate a desire to study, attend school, most preschoolers refuse to complete adult tasks or do it in their own way, the child is not ready to master literacy and reading.

Based on the results obtained, the content of the program was developed for the formation of motivational readiness, teaching literacy and reading for children with general speech underdevelopment "How good to be able to read!"

The purpose of the program: creation of effective psychological and pedagogical conditions in speech therapy classes aimed at the formation of motivational readiness, teaching literacy and reading to children with systemic speech disorders.

Program objectives:

1. Enrichment, consolidation, clarification, activation of the vocabulary of preschoolers with systemic speech disorders, elimination of non-literary words from speech (dialect, vernacular, slang).

2. Development of sound and intonation culture of speech, phonemic hearing (automation of sounds difficult for pronunciation in speech).

3. Formation of sound analytical-synthetic activity in preschoolers as a prerequisite for teaching literacy and reading (dividing words into syllables, sound analysis of words, etc.).

4. Development of mental processes in preschoolers of senior preschool age (attention, perception, memory, thinking, imagination, etc.).

5. Fostering interest in learning, positive motivation for further learning throughout subsequent life (at school, college, institute, university, etc.).

The program "How good to be able to read!" for children with systemic speech disorders is compiled based on the following principles:

- the principle of stimulating and motivating educational and cognitive activity in working with children of older preschool age;

- the principle of developmental education (orientation of the content of correctional and educational work with children to the zone of "proximal development of preschoolers according to LS Vygotsky); 
- combines the principles of scientific validity and practical applicability (corresponds to the theoretical provisions and concepts in the field of correctional pedagogy, preschool education, can be used when teaching preschoolers in other educational institutions);

- complies with the criteria of completeness, necessity and sufficiency (takes into account the psychological and pedagogical features of speech development of preschoolers with systemic speech disorders);

- built taking into account the principle of integration of various types of children's activities (speech, cognitive, social and communicative);

- based on the complex-thematic principle of presenting the content (the program presents a perspective-thematic plan for teaching literacy and reading to older preschool children);

- the educational process is built taking into account the leading type of activity of preschool children (verbal and cognitive games, speech situations, problem situations, etc.); - upbuild considering the principle of continuity of the content of preschool and primary education.

The program «How good to be able to read!» is aimed at the formation of motivational readiness for schooling children from senior preschool age, harmonious development of the child's personality (speech, social and communicative, cognitive); taking into account the individual and speech characteristics of preschool children (age, level of development of mental processes, gender differences); ensuring emotional well-being (creating a situation of success, emotional comfort, etc.); involves making changes to the developing subjectspatial environment (speech didactic games, magnetic alphabet, plot pictures, pictograms, etc.); the interconnection of the process of correction, development, training and education (development of mental processes, teaching literacy and reading, fostering the desire to learn, etc.).

As a result of mastering the working program «How good to be able to read!» the child will have a motivation to study at school, curiosity, the preschooler distinguishes between sounds and letters, differentiates isolated sounds in words, compares words in length, performs sound analysis of the word (pronounces words independently, emphasizing the first sound in them, recognizes words for a given sound, distinguishes vowels and consonants by ear), mastered reading by the method of syllable fusion based on a vowel, divides two or three syllable words into syllables, makes sentences with a given number of words, determines the number and sequence of words in a sentence.

The child understands generalizing words; correctly uses prepositions in speech; Cardinal numbers; distinguishes objects, actions and signs by numbers, gender and cases (differentiates the singular and plural forms of masculine and feminine nouns, etc.); uses nouns with diminutive suffixes; understands the singular and plural forms of verbs; uses various means of communication in speech; draws up simple sentences by distributing them as homogeneous members; proactive in communication, uses emotional and evaluative vocabulary.

Classes with older preschool children are held in a playful way twice a week, for about 20-35 minutes. The structure of the lesson: an interesting moment (receiving a letter, the appearance of heroes of famous cartoons, films, books, guessing and guessing riddles, etc.); examining illustrations, photographs, talking about their content, conducting virtual (real excursions), performing lexical and grammatical tasks (games, solving problem and speech situations, etc.); drawing up a descriptive story (based on a picture, from personal experience, descriptive riddles, etc.); tasks for teaching reading skills (working out articulation of sounds, reading syllables, differentiating sounds, reading words, sentences, speech games, writing for preschoolers); summing up, reflection. Particular attention is paid to motivational readiness for learning at school (viewing illustrations, videos about school life, reading poetry and stories, etc.). 
During the implementation of the program, technologies were systematized aimed at the formation of motivational readiness, teaching literacy and reading of children with OHP in speech therapy classes: didactic games ("What is a school?", "School professions", "Give it a single word", "School supplies", "The fourth extra", "I am a future student", "In the school library", etc.), excursions (real and virtual) ("In the first grade", "In the school cafeteria", "In the school gym", etc.), speech games ("Guess the first sound in a word", "Spell the word on the sound ...", "Guess what object the letter looks like", "Find the letter", "Cut pictures", "Guess the sound", "Friends words" , "The fourth extra", etc.), speech situations ("Make the object big-small", "Form a new word", etc.), examination of illustrations, photos (pictures) and a conversation on their content, work in writing, etc.

\section{Conclusion}

During the final stage of the experiment, a positive dynamics was revealed in the level of formation of motivational school-readiness for children of 6-7 years old with speech impairments: with a low level of school-readiness 2 children were found $10 \%$ of the subjects), an average level - 6 children (30\% of the subjects) and a high level of 12 preschoolers $(60 \%$ of children). Obviously, the children of the experimental group are dominated by an educational and cognitive motive, a desire to study, to attend school, the ability to perform given actions, preschoolers learned to read, perform literacy tasks: differentiate isolated sounds in words, compare words in length, carry out sound analysis of a word ( independently pronounces words, intonationally emphasizing the first sound in them, recognize words for a given sound, distinguish vowels and consonants by ear), divide two or three-syllable words into syllables, make sentences with a given number of words, determine the number and sequence of words in a sentence.

The experiment proved that the process of formation of motivational readiness to study at school for children with general speech underdevelopment will proceed effectively under the following conditions: the use of diagnostic examination data for preschoolers with systemic speech disorders will be in the process of planning work with them; development and testing of a program for the formation of motivational readiness, teaching literacy and reading for children with systemic speech disorders in speech therapy classes; the use of developmental technologies in the process of formation of motivational school-readiness for children with speech disorders.

\section{References}

1. N. V. Nizhegorodtseva, T. V. Zhukova, Complex Diagnostics Methodology of the Psychological Structure of Students, Learning Activities and Readiness to Study in Higher School, Yaroslavl Pedagogical Bulletin, 2, 119-123 (2015)

2. L. A. Golovcic, O. V. Becker, To the problem of the formation of professional competences of students in the process of preparing to work with children with complex violations, Defectology, 2, 80-87 (2015)

3. N. I. Gutkina, Psychological readiness for school in the context of the problem of continuity between preschool and school education, Psychological Science and Education, 15, 3 (2010)

4. I. Yu. Levchenko, I. V. Evtushenko, Professional standard of pedagogue-defectologist: perspectives, improvement, practice, Special education, 1(57), 136 (2020) DOI 10.26170/sp20-01-10 
5. I. A. Emelyanova, E. A. Borisova, O. E. Shapovalova, O. V. Karynbaeva, I. M. Vorotilkina, Particularities of Speech Readiness for Schooling in Pre-School Children Having General Speech Underdevelopment: A Social and Pedagogical Aspect, Journal of Social Studies Education Research, 201:98, 1, 89-105

6. H. Shlomo, U. Hess, The Reverse Engineering of Emotions - Observers of Others' Emotions as Naïve Personality Psychologists, 13 December, 103-118 (The Social Nature of Emotion Expression, 2019)

7. A. Iqra, R. Omar, S. A. Panatik, A Literature Review on Personality, Creativity and Innovative Behavior, 6(1), 177-182 (International Review of Management and Marketing, 2016)

8. W. Pei - Jung, A.W. Hwang, The stability of mastery motivation and its relationship with home environment in infants and toddlers, 34, 434-442, Infant Behavior and Development (2011)

9. S. R. Zentall, B. J. Morris, «Good job, you are so smart»: The effects of inconsistency of praise type on young children's motivation, Journal of Experimental Child Psychology, 107, 2, 155-163 (2010)

10. P. A. McDermott, The Preschool Learning Behaviors Scale: Dimensionality and External Validity in Head Start, School Psychology Review, 41, 66-81 (2012)

11. P. Haidkind, E. Kikas, H. Henno, T. Peets, Controlled Drawing Observation for Assessing a Child's Readiness for School and Predicting Academic Achievement at the End of the First Grade, Scandinavian Journal of Educational Research, 55(1), 61-78 (2011)

12. M. Prior, E. Bavin, B. Ong, Predictors of school readiness in five? to six--year--old chil dren from an Australian longitudinal community sample, Educational Psychology, 31(1), 3-16 (2011)

13. S. L. Bender, A. V. Pham, J. S. Carlson, School Readiness (Encyclopedia of Child Behavior and Development, 2011) DOI: https://doi.org/10.1007/978-0-387-790619_2506.

14. C. Cipriani, R. Sassu, M. Controzzi, M. C. Carrozza, Influence of the weight actions of the hand prosthesis on the performance of pattern recognition based myoelectric control: preliminary study, Annual International Conference of the IEEE Engineering in Medicine and Biology Society (2011) DOI: 10.1109/IEMBS.2011.6090468

15. M. Guhn, A. Gadermann, C. Hertzman, B. Zumbo, Children's development in kindergarten: a multilevel, population-based analysis of ESL and gender effects on socioeconomic gradients, Child Indicators Research, 3(2), 183-203 (2010)

16. M. Janus, S. Brinkman M. Guhn, Early Development Instrument, Encyclopedia of Quality of Life and Well-Being Research (2014) DOI: https://doi.org/10.1007/978-94007-0753-5_3439

17. A. Mousavi, V. Krishnan, Setting the scope for early child Development Instrument (EDI): a psychometric reexamination of the tool with Alberta data, Social Indicators Research, 122(3), 925 (2015)

18. J. Baumbusch, J. E. V. Lloyd, Using Research Priority Setting to Investigate Special Education in British Columbia, Paediatrics \& Child Health, 39 (2020) DOI: 10.1093/pch/pxaa068.093

19. P. A. McDermott, The Preschool Learning Behaviors Scale: Dimensionality and External Validity in Head Start, School Psychology Review, 41(1), 66-81 (2012) 
20. K. Hee-Ju, P. A. McDermott, A. M. Barsevick, Comparison of Groups With Different Patterns of Symptom Cluster Intensity Across the Breast Cancer Treatment Trajectory, Cancer Nursing, 37(2), 88-96 (2014) doi: 10.1097/NCC.0b013e31828293e0

21. G. Melzi, A. R. Schick, K. Escobar, Early Bilingualism Through the Looking Glass: Latino Preschool Children's Language and Self-Regulation Skills, Annual Review of Applied Linguistics, 37, DOI: https://doi.org/10.1017/S0267190517000083

22. S. M. Valavko, Comparative-comparative analysis of the development of the motivational sphere of older preschoolers in the norm and with disorders of speech development, System Psychology, 4(12), 65-73 (2014) 